\title{
Estudo epidemiológico das variáveis sociodemográficas associados aos casos notificados de meningite no estado do Piauí
}

Epidemiological study of sociodemographic variables associated with notified cases of meningitis in the state of Piauí

Estudio epidemiológico de variables sociodemográficas asociadas a casos notificados de meningitis en el estado de Piauí

\section{Resumo}

Introdução: A meningite infecciosa é um importante problema de saúde pública mundial. No Brasil, é um tipo de doença de notificação compulsória. Objetivo: Este estudo teve como objetivo geral traçar o perfil sociodemográficos dos casos notificados de Meningite no estado do Piauí entre os anos de 2010 a 2020. Metodologia: Trata-se de uma revisão retrospectiva e descritiva com estudo quantitativo. O estudo constituiu-se de uma avaliação das informações obtidas, o qual teve início nas bases de dados do SINAN. Resultados e Discussão: Verificou-se 2.458 casos notificados de meningite no período de 2010 a 2020, com maior número dos casos no sexo masculino 1.498 (60,94\%) e na faixa etária de 20-30 anos com 681 casos $(27,71 \%)$. Verificou-se que 221 (8,99\%) pacientes evoluíram para óbito e $2.040(82,99 \%)$ pessoas tiveram alta. Consegue encontrar-se na zona urbana com $1.887(76,77 \%)$ número de residentes e em estudantes da $5^{\mathrm{a}}$ a $8^{\mathrm{a}}$ série incompleta do Ensino Fundamental, com 536 casos (21,81\%). Conclusão: 
Contudo, de acordo com os resultados obtidos neste estudo são primordiais as ações em saúde voltadas para pessoas de baixa escolaridade, além de conter maiores investigações frente o agravo nessa faixa etária e o monitoramento da vigilância epidemiológica sob a transmissão da doença.

Palavras-chave: Epidemiologia; Meningite; Saúde pública.

\begin{abstract}
Introduction: Infectious meningitis is an important public health problem worldwide. In Brazil, it is a type of disease with mandatory notification. Objective: This study aimed to outline the sociodemographic profile of reported cases of Meningitis in the state of Piauí from 2010 to 2020. Methodology: This is a retrospective and descriptive review with a quantitative study. The study consisted of an evaluation of the information obtained, which began in the SINAN databases. Results and Discussion: There were 2,458 reported cases of meningitis in the period 2010 to 2020 , with the highest number of cases in males $1,498(60.94 \%)$ and in the age group of 20-30 years with 681 cases $(27.71 \%)$. It was found that $221(8.99 \%)$ patients died and 2,040 (82.99\%) people were discharged. It manages to find itself in the urban area with $1,887(76.77 \%)$ number of residents and students from the 5th to 8th incomplete grade of elementary school, with 536 cases $(21.81 \%)$. Conclusion: However, according to the results obtained in this study, health actions aimed at people with low education are paramount, in addition to containing further investigations on the problem in this age group and monitoring of epidemiological surveillance on the transmission of the disease.
\end{abstract}

Keywords: Epidemiology; Meningitis; Public health.

\title{
Resumen
}

Introducción: la meningitis infecciosa es un importante problema de salud pública a nivel mundial. En Brasil, es un tipo de enfermedad con notificación obligatoria. Objetivo: Este estudio tuvo como objetivo delinear el perfil sociodemográfico de los casos reportados de Meningitis en el estado de Piauí de 2010 a 2020. Metodología: Se trata de una revisión descriptiva retrospectiva con un estudio cuantitativo. El estudio consistió en una evaluación de la información obtenida, que se inició en las bases de datos del SINAN. Resultados y Discusión: Se notificaron 2.458 casos de meningitis en el período 2010 a 2020, siendo el mayor número de casos en varones $1.498(60,94 \%)$ y en el grupo de edad de 20-30 años con 681 casos $(27,71 \%)$. Se encontró que $221(8,99 \%)$ pacientes fallecieron y 2.040 $(82,99 \%)$ personas fueron dadas de alta. Se las arregla para ubicarse en el casco urbano con $1.887(76,77 \%)$ número de residentes y alumnos de $5^{\circ}$ a $8^{\circ}$ grado incompleto de la escuela primaria, con 536 casos $(21,81 \%)$. Conclusión: Sin embargo, de acuerdo con los resultados obtenidos en este estudio, las acciones de salud dirigidas a personas con bajo nivel educativo son primordiales, además de contener nuevas investigaciones sobre la problemática en este grupo etario y el seguimiento de la vigilancia epidemiológica sobre la transmisión de la enfermedad.

Palabras clave: Epidemiología; Meningitis; Salud pública.

\section{Introdução}

A meningite é uma doença infectocontagiosa ocasionada pela inflamação da meninge, sobretudo pelo espaço subaracnóideo, é passivel de atingir o segmento cranial e medular. É uma patologia geralmente associada a bactérias ou vírus, porém parasitas, fungos e até causas não infecciosas podem levar à meningite, sendo são mais raras. (Souza, et al., 2020). São majoritárias as meningites virais, Nesse estudo e ao que se retrata na literatura com possibilidade de evoluir para o perecimento em horas ou até 2(dois) dias, em razão de seu progresso rápido (Monteiro, 2020).

Existem diversas bactérias causadoras da meningite, os principais agentes no Brasil são: Neisseria meningitidis, Streptococcus sp, Streptococcus pneumoniae, Listeria monocytogenes, Mycobacterium tuberculosis, Escherichia coli, Treponema pallidum e Haemophilus influenzae. Essas espécies de bactéria apresentam 12 diferentes sorogrupos, os principais constituem A, B, C, X, Y e W-135 que são capazes de se multiplicar, não apenas pelo líquor, mas também no sangue, ocasionando bacteremia e quando há um progresso, acarreta para sepse (Silva, 2021).

A infecção viral, normalmente, se estabelece no período entre 7 a 10 dias e raramente deixa sequelas, entretanto na bacteriana estas infecções são bem frequentes (Silva, 2021). Na infecção bacteriana, a transmissão ocorre de forma interpessoal por gotículas das vias respiratórias e/ou secreções da nasofaringe, tornando-se necessário um contato íntimo, como habitar o mesmo local ou no contato direto com as secreções respiratórias que podem decorrem na transmissão, os sintomas manifestamse nos 3 a 4 dia. Logo, na viral, sua transmissão predomina a via fecal-oral, ocorrendo por via respiratória, tendo um período de incubação em média de 7 a 14 dias. O quadro clínico do paciente independe de sua etiologia pode apresentar como sinais e 
sintomas: vômito, cefaleia, petéquias, febre, rigidez da nuca, sinal de Kernig e/ou Brudzinski e quando grave pode levar ao fim da vida (Paim, 2019).

A identificação do agente etiológico da meningite é fundamental para iniciar o tratamento especifico do patógeno, o diagnóstico é executado pela análise do líquido cérebro-espinhal - LCE (líquor) e amostras de sangue. Habitualmente realiza-se a bacterioscopia direta (líquor), exame quimiocitológico do líquor, cultura (líquor, sangue, petéquias ou fezes), contra-imuneletroforese cruzada - CIE (líquor e soro) e aglutinação pelo látex (líquor e soro). O aspecto do líquor auxilia como um indicativo, não equivalendo a ser considerado um exame, seu aspecto normal é de caráter límpido e incolor. Em processos infecciosos, ocorre o aumento de elementos figurados (células), causando turvação, cuja intensidade varia de acordo com a quantidade e o tipo desses elementos (Brasil, 2019; Monteiro et al., 2020; Cruz, 2021).

As meningites contém distribuição mundial e são apontadas como um sério problema de saúde pública pela sua magnitude, potencial de transmissão, patogenicidade e relevância social. Além de integrar-se no grupo de doenças com notificação imediata. No Brasil, é uma doença endêmica com acontecimento de surtos e epidemias ocasionais, associado ao cenário precário de saneamento básico e fatores socioeconômicos (Brasil, 2019; Monteiro et al., 2020).

De acordo com os dados da Organização Mundial da Saúde (OMS), estima-se que haja no mundo, em torno de 1,2 milhões de casos e 135 mil mortes por meningite a cada ano. Sua distribuição é mundial e sua incidência varia de acordo com a região, estando associada aos aspectos climáticos, a existência de aglomerados, as características socioeconômicas e a circulação do agente no ambiente. Mesmo com o diagnóstico precoce e o tratamento adequado, cerca de 5\% a 10\% dos casos vão ao falecimento. Frequentemente, após 24 ou 48 horas do surgimento dos primeiros sintomas, sem o tratamento adequado pode resultar na morte dos pacientes (Brasil, 2020).

A taxa de letalidade é alta, porém pode evitar-se os principais agentes bacterianos por meio da vacinação. A criança é vacinada com a Pentavalente aos 2 meses de idade, com reforço aos 4 e aos 6 meses, que previne de infecções pelo Haemophilus influenzae tipo B. A vacina meningocócica conjugada é efetuada aos 3 e 5 meses e um reforço aos 12 meses, que protege de infecções pelo Neisseria meningitidis do sorogrupo C. A vacina pneumocócica 10-valente (conjugada) é efetuada aos 2 e 4 meses e um reforço aos 12 meses, que previne contra doenças invasivas e otite média aguda causadas por Streptococcus pneumoniae sorotipos 1, 4, 5, 6B, 7F, 9V, 14, 18C, 19F e 23F. A BCG é efetuada ao nascer, de dose única, que protege contra formas graves de meningite (Brasil, 2020). Seu tratamento corresponde conforme a etiologia da doença, e em seguida executa-se o tratamento de suportivo ao paciente (Cruz, et al., 2021).

A partir dessas ponderações é possível determinar a relevância dos estudos epidemiológicos acerca de doenças de notificação compulsória. Portanto, este estudo obteve como objetivo geral traçar o perfil sociodemográficos dos casos notificados de Meningite no estado do Piauí entre os anos de 2010 a 2020.

\section{Metodologia}

Trata-se de uma revisão retrospectiva (Diniz, 2019), transversal (Cruz, 2021) e descritiva (Brito, 2019) com estudo quantitativo. Incluímos os casos notificados de meningite no estado do Piaú entre os anos de 2010-2020, apresentando a faixa etária, sexo, escolaridade, zona de residência e evolução da patologia.

Realizou-se a execução da pesquisa pela plataforma eletrônica do Departamento de Informática do Sistema Único de Saúde (DATASUS) através da opção >> "Acesso à informação" >> "Informações em Saúde (TABNET)" > "Epidemiológicas e Morbidade" >> "Doenças e Agravos de Notificação - De 2007 em diante (SINAN)" >> "Casos de Meningite". Os dados foram organizados em tabelas e gráficos descritivos e analíticos. A análise dos dados foi realizada pelo software Microsoft Excel 2019. 


\section{Resultados e Discussão}

O estudo considerou todos os casos notificados de meningite no estado do Piauí no intervalo de tempo 2010 a 2020 totalizando 2.458 casos notificados. De acordo com os dados notificados de meningite, o sexo masculino (n: 1.498/ 60,94\%) é predominante em relação ao sexo feminino (n: 960/ 39,06\%) (demonstrado no Gráfico 1).

Os dados encontrados na literatura referentes a pesquisas realizadas no mundo, afirma a predominância dos casos da doença em pacientes do sexo masculino é confirmado no Brasil, nos estados do Rio de Janeiro e São Paulo (POBB, 2013). Essa maior susceptibilidade da doença no sexo masculino é comprovada com os estudos de análise de prontuários que revelaram distribuição de 60\% dos pacientes do sexo masculino e 40\% do sexo feminino (FONTES, 2018).

De acordo, com Cruz (2021), Brito (2019), Fontes (2018), Cardoso e outros autores (2019) observaram majoritariamente prevalência de casos do sexo masculino, chegando a quase $60 \%$, assim como neste presente trabalho. Portanto, a associação entre os casos de meningite e sexo do paciente pode ser diferente, mesmo em pequena escala, dependendo da localização geográfica.

A frequência no número de casos masculino pode não relacionar-se a baixa imunidade, mas a perspectiva da série de trabalhos duplicados, em extração de petróleo, fábricas, mineração, entre outras, no qual o aglomerado e enclausuramento contribuem para transmissão do patógeno. Através deste estudo, é evidente a elevação da presença dessa doença em pacientes, este parâmetro também se notou em outras pesquisas efetuadas no estado e em demais estados do país, como Mina Gerais, Santa Catarina, Goiás (GONÇALVES, et al., 2020).

Todos esses resultados corroboram com os dados encontrados no gráfico acima, apresentando o sexo masculino como mais afetado pela meningite nesse estudo e ao que se retrata na literatura. Com relação a ascensão dos casos de meningite, 221 casos foram a óbito nos anos de 2010 a 2020 (Gráfico 1).

Gráfico 1: Demonstrativos dos casos confirmados de meningite por sexo do indivíduo, no estado do Piauí, no período de 2010 a 2020 .

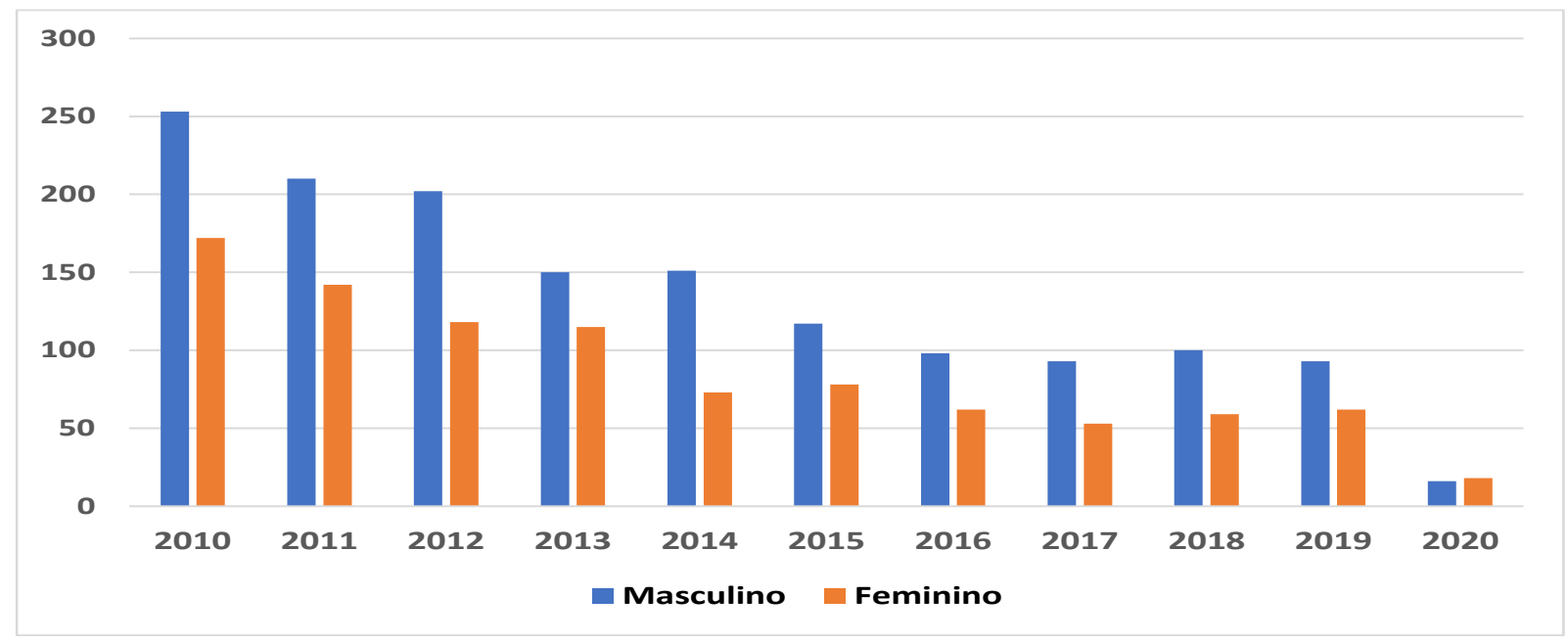

Fonte: DATASUS (2021).

Na evolução dos casos, cerca de 220 (8,99\%) dos pacientes faleceram. Dos pacientes diagnosticados de 2010-2020, por volta de $82,99 \%$ evoluíram para alta (2.040 pessoas), corroborando com os encontrados na literatura em que $89 \%, 85,3 \%$ e $80 \%$ dos indivíduos tiveram alta (Silva, 2018). 
De acordo com a literatura, no aumento dos casos, analisou-se que os óbitos decorreram em percentuais de $50 \%$ em meningite asséptica e 50\% em meningites bacterianas, procedente a observar medidas de proteinorraquia de $297,17 \mathrm{mg} / \mathrm{dL}$ em relação a 95,74mg/dL dos indivíduos que sobreviveram (Dazzi, 2014).

De acordo com Diniz (2019), o desenvolvimento desordenado de municípios superpopuloso, com condições vulneráveis para prover os requisitos necessários de uma organização social como educação, saúde e saneamento básico promovem a disseminação de imensuráveis agravos de saúde, aumentando significativamente os episódios de casos de meningite e, portanto, de mortes.

Por meio do diagnóstico precoce e o tratamento adequado, a meningite está otimizando o seu prognóstico, acrescentando o número de evoluções benéficas da doença que resultam em sua alta e cura. A maioria dos estudos que avaliam o prognóstico das meningites mostrou redução no número de óbitos (Guimarães, 2017; Monteiro, 2020; Brito, 2019), no qual notou-se, igualmente, neste estudo.

Contudo, devido à subnotificação estadual da doença, o número de casos ainda é subestimado, limitando o estudo. Ao mesmo tempo, a utilização da coleta de dados para a pesquisa é de grande relevância para orientar e organizar as ações de saúde direcionadas. Portanto, uma pesquisa colaborativa com ações do plano de prevenção e promoção da saúde (Cruz, 2021). Com relação à faixa etária, o número de casos notificados, ocorreram entre pessoas de 20-39 anos (n: 681 / 27,71\%) (Gráfico 2).

Gráfico 2: Casos confirmados de meningite, por evolução, no estado do Piauí, 2010 a 2020.

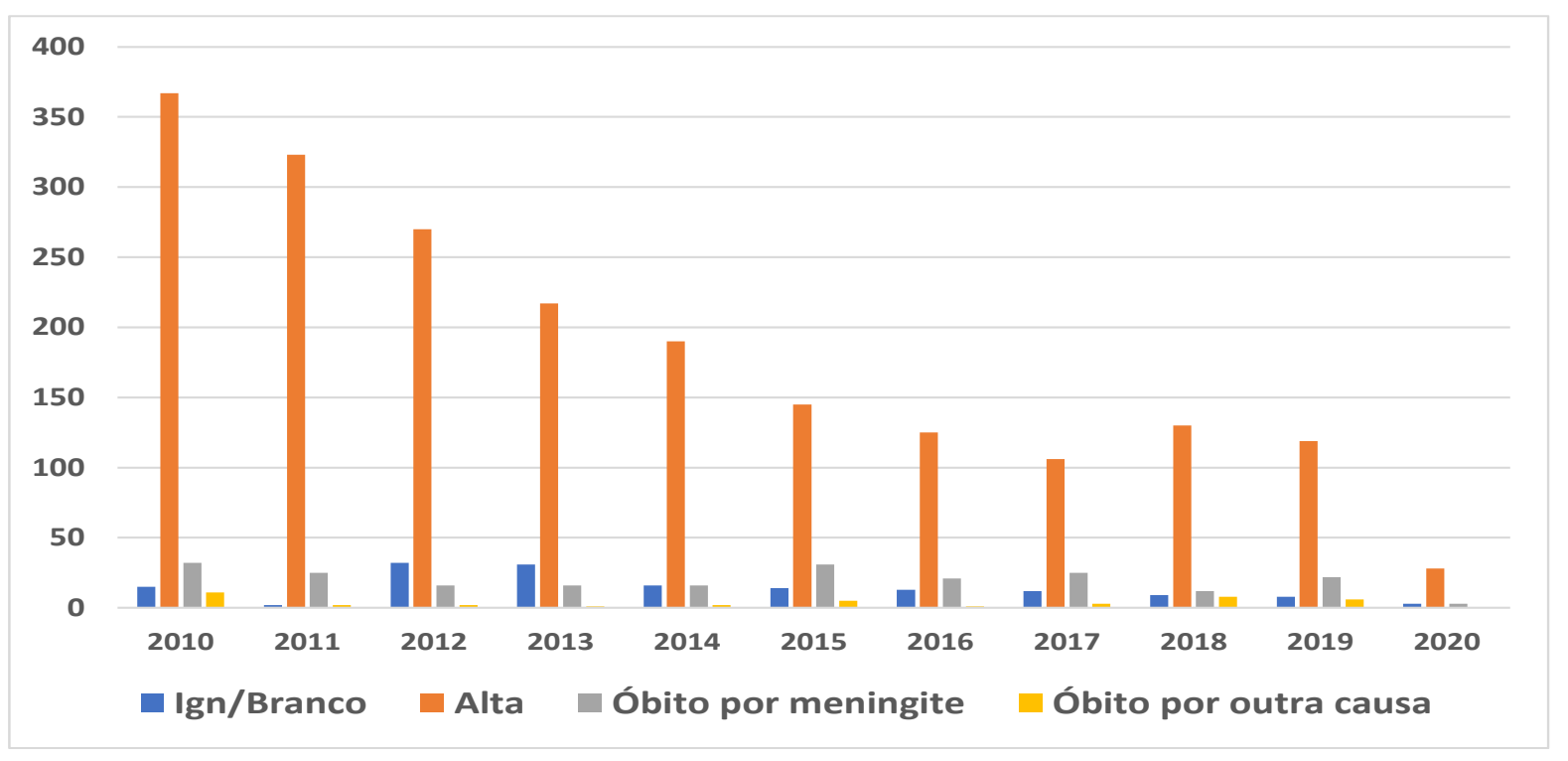

Fonte: DATASUS (2021).

$\mathrm{Na}$ representação gráfica ilustrada acima é analisado o predomínio de casos de meningite entre as faixas etárias, contendo um total de 2.458 entre todos os indivíduos, com um excedente número de casos em jovens de 20-39 anos que são os mais acometidos pela doença com 681 casos (27,71\%), em seguida pelos adultos de 40-59 anos com 385 casos (15,66\%) e em terceiro lugar crianças de 5-9 anos com 349 casos $(14,20 \%)$.

Em relação à faixa etária de predominância, Monteiro e outros autores (2020) demonstraram uma vantagem significativa na população de 20-29 anos no estado do Pará, corroborando os resultados do presente estudo. A faixa etária dos jovens e adultos de 20-39 anos, são os principais atingidos, fato este que é explicado por frequentarem instituições de ensino, onde os indivíduos permanecem aglomerados em espaço reduzido (Cruz, et al., 2021). 
Os adultos, jovens e crianças são as faixas etárias mais acometidas devido o sistema imunológico das crianças ainda estar em desenvolvimento, indicando um elevado risco para o crescimento de quadros infecciosos invasivos, pela permanência em ambientes de pequeno espaço e com grande número de pessoas (Gonçalves, et al., 2020). Apesar da grande diversidade do nível de instrução, $536(21,81 \%)$ de casos dessa doença, correspondente ocorreu entre os alunos da $5^{\mathrm{a}}$ a $8^{\mathrm{a}}$ série incompleta do Ensino Fundamental (Gráfico 3).

A escolaridade da $5^{\mathrm{a}}$ a $8^{\mathrm{a}}$ série incompleta do Ensino Fundamental, são os mais afetados com 536 casos $(21,81 \%)$, em segundo o Ensino Fundamental completo com 339 casos $(13,79 \%)$ e em terceiro a $1^{\text {a }}$ a $4^{\text {a }}$ série incompleta do Ensino Fundamental com 231 casos $(9,40 \%)$.

De acordo com a literatura, a meningite viral não é muito discutida sobre a intervenção da pobreza e acesso regular à assistência à saúde e a preponderância desta doença. A elevada prevalência de infectados com baixa escolaridade pode ser atribuída principalmente à falta de informação e consequente desconhecimento da importância e das medidas preventivas para prevenir o possível desenvolvimento de meningites e outras doenças infecciosas (Junior, 2018).

Crianças de creches ou em fase de escolaridade são mais cometidas de acordo com a perspectiva epidemiológica. Ocorrendo devido a diversos motivos, seja pelo sistema imunológico em desenvolvimento ou pela exposição de novos agentes infecciosos. Além da própria coabitação com outras crianças com estas características em ambientes fechados. A preponderância da incidência de contaminação é prevalente nas estações de inverno e outono, logo os ambientes tendem a ficarem fechados (IFF / FIOCRUZ, 2017). Ao examinar a zona de residência considerou o predomínio dos indivíduos residentes da zona urbana, com 1.887 casos (76,77 \%) (Gráfico 4).

Gráfico 3: Casos confirmados de meningite por faixa etária, no estado do Piauí, 2010 a 2020.

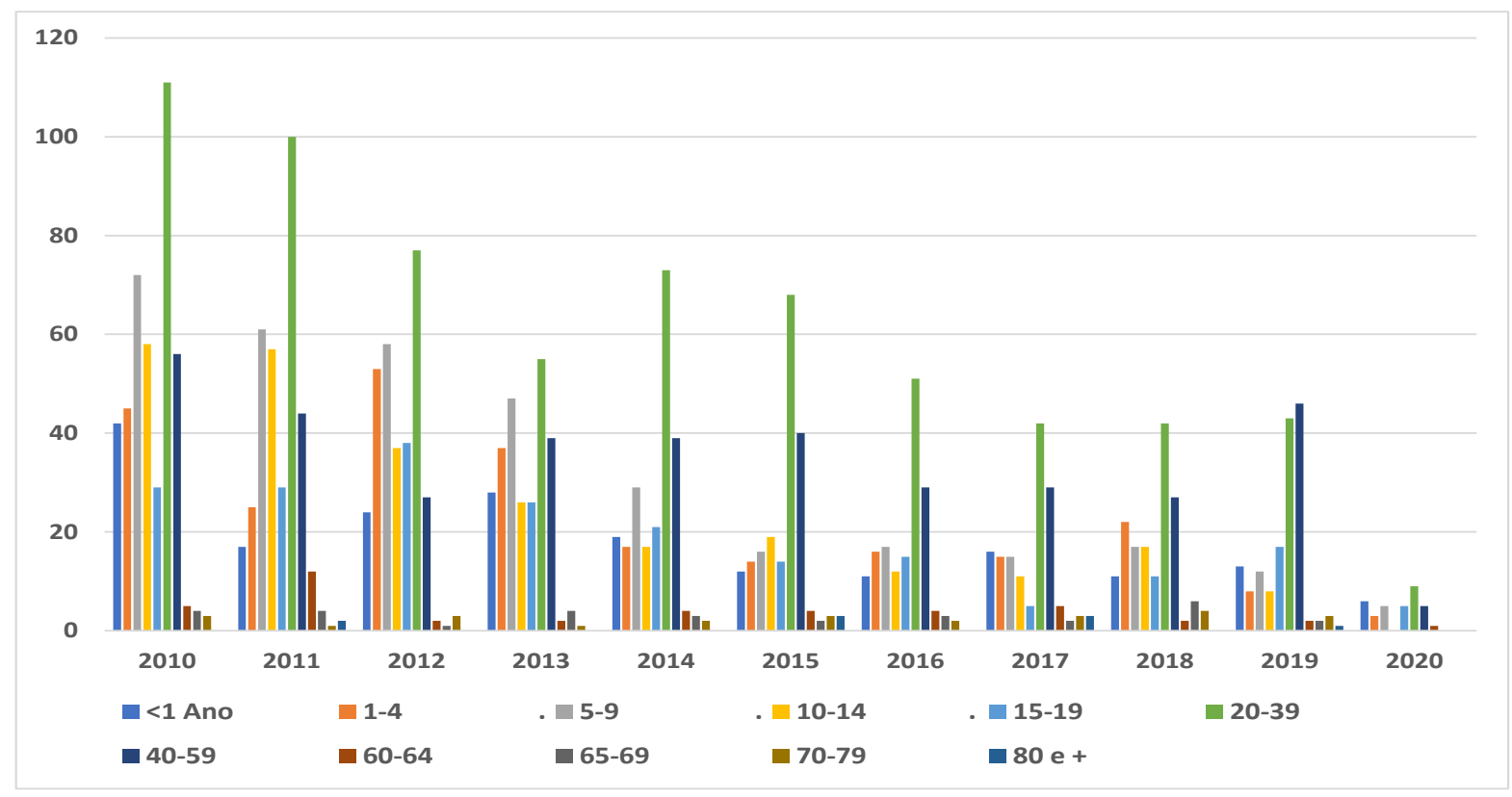

Fonte: DATASUS (2021). 
Gráfico 4: Casos confirmados de meningite por escolaridade, no estado do Piauí, 2010 a 2020.

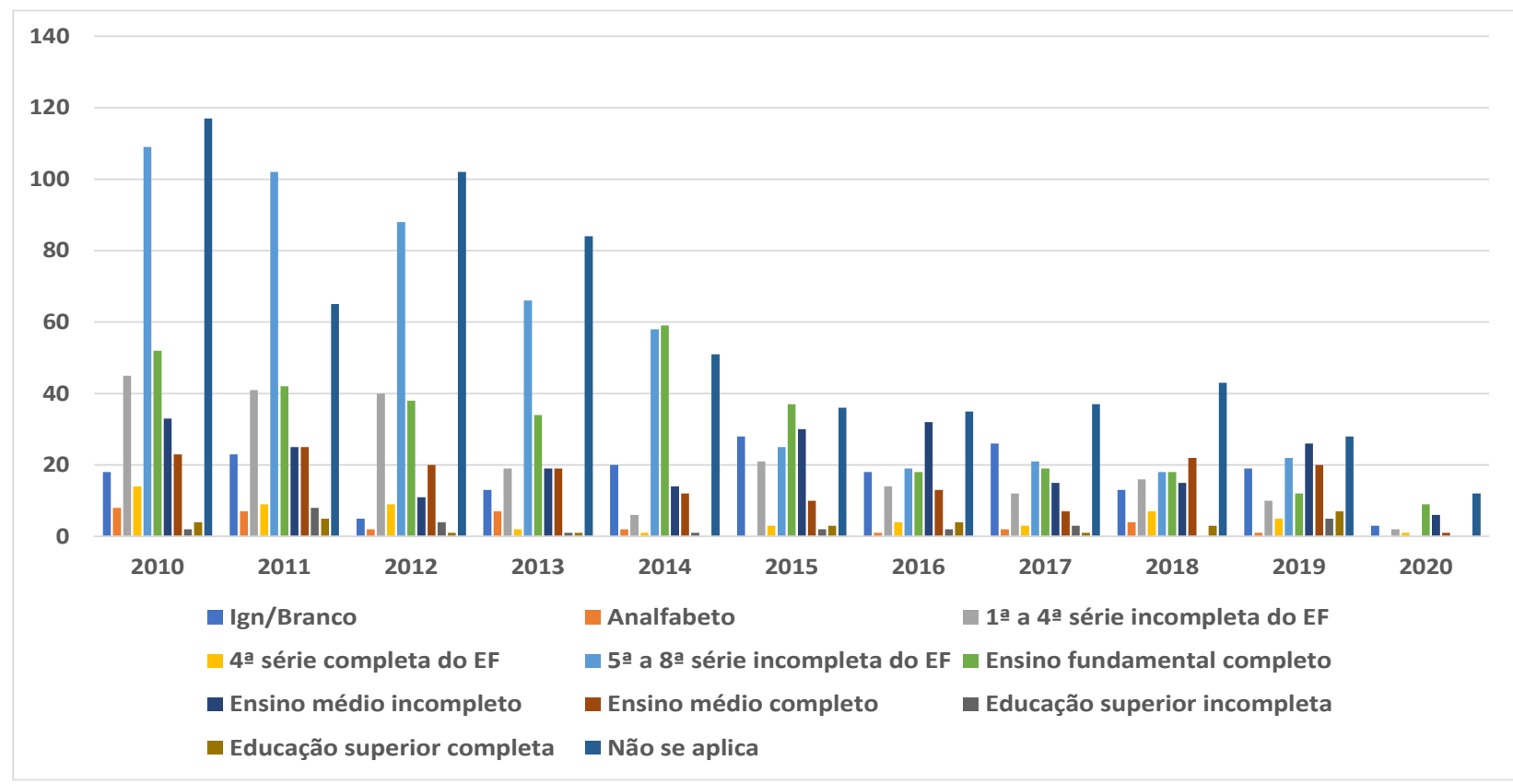

Fonte: DATASUS (2021).

Nesta perspectiva, a zona urbana apresentou 1.887 (76,77\%) número de residentes, em segundo lugar a zona rural com 505 casos $(20,55 \%)$ e na zona periurbana somente obteve 1 casos $(0,04 \%)$, totalizando 2.458 casos por zona de residência (Gráfico 5).

Gráfico 5: Casos confirmados de meningite por zona de residência, no estado do Piauí, 2010 a 2020.

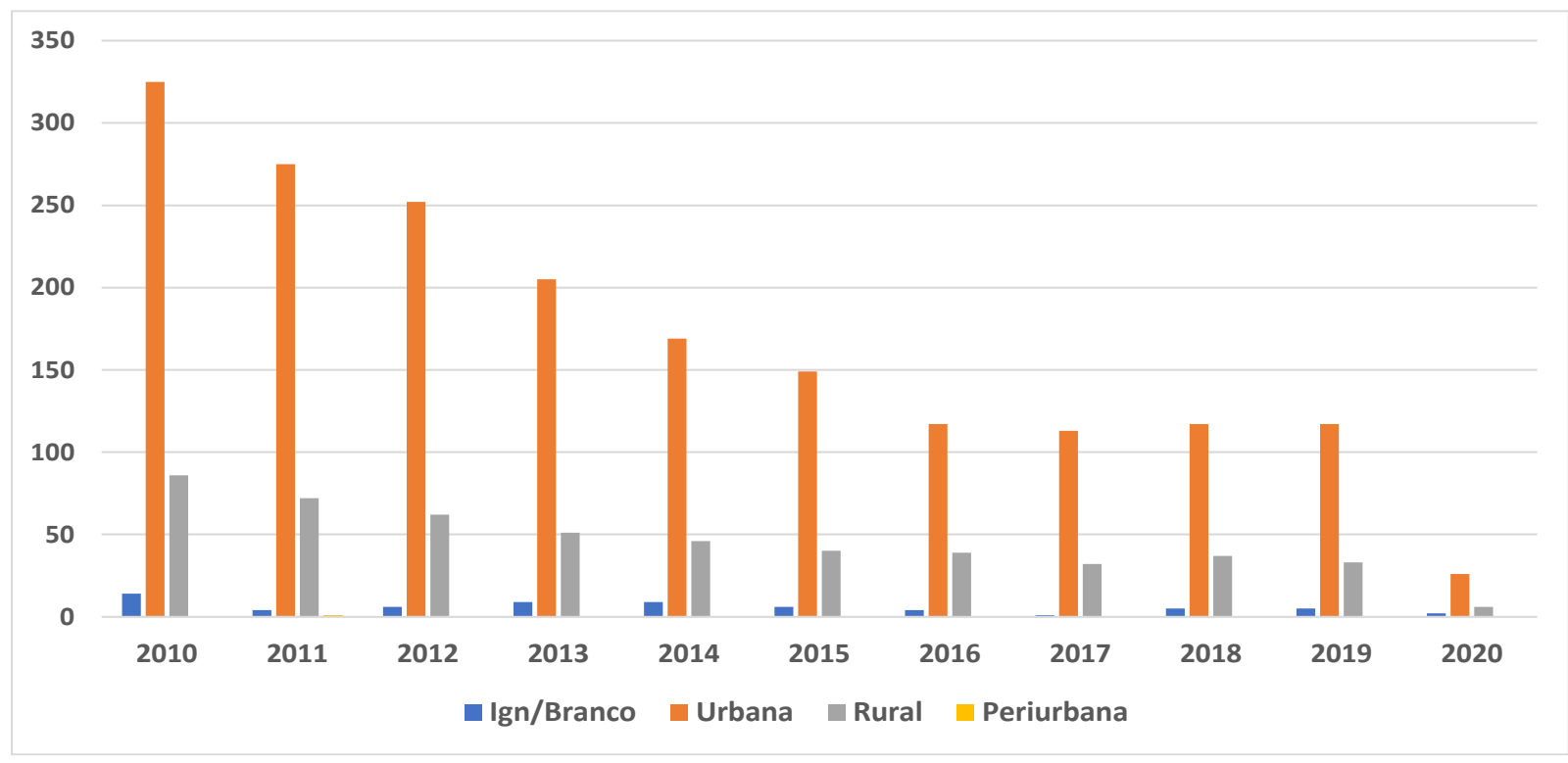

Fonte: DATASUS (2021).

O aumento do número de casos de meningite é devido o acréscimo de moradia na zona urbana, além da convivência em ambientes fechados e com um abundante número de pessoas, que estimulam a propagação de patógenos responsáveis pela etiologia da doença (Cruz, et al., 2021). 
Do ponto de vista da pesquisa municipal, com espaços mais delimitados, entende-se que as regiões periféricas das cidades possuem uma incidência de meningite maior, desse modo a epidemia começa nas periferias e concentra-se nas zonas centrais da cidade (Lima, 2021), que ocorre devido ao acréscimo populacional desordenado nas cidades com o precário saneamento básico, baixo índice de informação e qualidade de vida (Monteiro, 2020).

Constata-se que os casos eram residentes da zona urbana (84-96,44\%) e possuem baixa escolaridade (Lima, 2021). Por meio de estudos municipais, pode-se perceber que em áreas com mais regiões delimitadas, a incidência de meningites é dominante nas áreas periféricas da cidade, portanto, a epidemia obteve início no entorno e se espalhou de forma concêntrica para a área central da cidade (Monteiro et al., 2020).

\section{Conclusão}

Ao considerar os resultados deste estudo epidemiológico, é notório que os resultados do Piauí são semelhantes aos de outros estudos e estados. Por meio do estudo epidemiológico, verificou-se a predominância de casos no sexo masculino com as faixas etárias de 20-39 anos, tornando-se os mais acometidos pela meningite, observa-se o maior número dos casos na zona urbana com 1.887 casos, desses 221 casos evoluíram para óbito e 2.040 pessoas evoluíram com alta. Constatou-se que a população mais atingida possui um baixo grau de escolaridade, em alunos da $5^{\mathrm{a}}$ a $8^{\mathrm{a}}$ série incompleta do Ensino Fundamental, com 695 casos.

Contudo, de acordo com os resultados obtidos na pesquisa é primordial as ações em saúde voltadas para pessoas de baixa escolaridade, além de conter maiores investigações frente o agravo na faixa etária dos 20-39 anos e o monitoramento da vigilância epidemiológica sobre a transmissão da doença, os dados obtidos nessa pesquisa podem fornecer base para novas pesquisas.

\section{Referências}

Brasil. Ministério da Saúde. (2019). Meningite: o que é, causas, sintomas, tratamento, diagnóstico e prevenção. https://antigo.saude.gov.br/saude-de-az/meningites\#: :text=A\%20meningite\%20\%C3\%A9\%20uma\%20inflama\%C3\%A7\%C3\%A3o,pode\%20acontecer \% 20em\%20qualquer\%20idade.

Brasil. Ministério da Saúde. (2020). Secretaria de Políticas de Saúde. Boletim Epidemiológico. N¹ Ceará - 03/07/2020. https://www.saude.ce.gov.br/wpcontent/uploads/sites/9/2018/06/BOLETIM_MENINGITE_03_07_2020.pdf.

Brasil. Ministério da Saúde. (2019). Secretaria de Políticas de Saúde. Boletim Epidemiológico. Volume 50- ํo3 | Jan. Meningite bacteriana não especificada no Brasil 2007 - 2016: desafio para a vigilância das meningites. https://antigo.saude.gov.br/images/pdf/2019/fevereiro/01/2018-038.pdf

Brito, R. C. V. Peres, C. L. Silveira, K. A. F. \& Arruda, E. L. (2019) Análise epidemiológica da meningite no estado de Goiás. Revista Educação em Saúde. 7(2), 83-90. https://doi.org/10.29237/2358-9868.2019v7i2.p81-88

Cardoso, L. C. C. Santos, M. K. A. \& Mariano, N. F. (2019). Caracterização do perfil epidemiológico de meningite: estudo ecológico na Região Nordeste de 2008 a 2018. $2^{\circ}$ Congresso Internacional de Enfermagem - CIE/13 ${ }^{\circ}$ Jornada de Enfermagem da Unit (JEU) - 6 a 10 maio. https://eventos.set.edu.br/cie/article/view/11597

Cruz, S Bernardo, T. \& Gusmão, W. (2021). Incidence of Meningitis between the years 2015 to 2019 in the State of Alagoas. Brazilian Journal of Health Review, 4(1), 2102-2113, 10.34119/bjhrv4n1-171

Dazzi, M. C. Zaatti, C. A. \& Baldissera, R. (2014). Perfil dos Casos de Meningite Ocorridas no Brasil de 2009 à 2012. Revista UNINGÁ Review 19(3), 33-36 http://revista.uninga.br/index.php/uningareviews/article/view/1545/1157

Diniz, L. F. A. (2019). Análise de dados das meningites infecciosas registradas na região da baixada santista (2007 A 2017). Trabalho de Conclusão de Curso (Especialização-Vigilância Laboratorial em Saúde Pública)- Secretaria de Estado da Saúde de São Paulo - Instituto Adolfo Lutz. https://docs.bvsalud.org/biblioref/2019/06/999679/ial_dinizlfa.pdf

Fontes, F. L. L. (2018). Epidemiological aspects q meningite in the state of piaui: 2007 to 2017.Revista Ciência Saberes - Facema, 4 (3), 1303. http://www.facema.edu.br/ojs/index.php/ReOnFacema/article/view/573.

Gonçalves, D. N. Delfino, I. M. D. A. S. \& Junior, R. N. C. M. (2020). Aspectos epidemiológicos da meningite no Estado do Piauí, Brasil, em 2018. Pesquisa, Sociedade e Desenvolvimento, 9 (11), e82891110260. https://doi.org/10.33448/rsd-v9i11.10260. 
Research, Society and Development, v. 11, n. 1, e26211124749, 2022

(CC BY 4.0) | ISSN 2525-3409 | DOI: http://dx.doi.org/10.33448/rsd-v11i1.24749

Guimarães, M. G. B. (2017). Perfil epidemiológico dos casos confirmados de meningite em Ituiutaba-MG. Tese (Bacharel em Ciências Biológicas). Faculdade de Ciências Integradas do Pontal, Ciências Biológicas, Universidade Federal de Uberlândia. Minas Gerais. https://repositorio.ufu.br/bitstream/123456789/21187/5/PerfilEpidemiologicoCasos.pdf.

Junior, F. P. A. Alves, T. W. B., \& Barbosa, V. S. A. (2018). Perfil de acometidos por meningite em natal-rn entre os anos de 2010 a 2017 : Um Estudo Documental. Anais CONADIS - Congresso Nacional de Diversidade do Semiárido - Campina Grande: Realize Editora. 〈https://editorarealize.com.br/artigo/visualizar/50799>.

Lima, D. M. N. \& Patriot, A, G. C. (2020). A incidência das meningites no Nordeste: um estudo ecológico de 13 anos. Scire Salutis. out2020-jan2021, Vol. 11 Edição 1, 98-109. 12p.10.6008/CBPC2236-9600.2021.001.0011

IFF/Fiocruz. (2017). MENINGITE: Entenda a doença. http://www.iff.fiocruz.br/index.php/8-noticias/357-meningite.

Monteiro, M. C. S. Corrêa, G. F. C. Monteiro, J. A. M. C. Ferreira, L. C. Junior, E. G. S. \& Gomes, S. T. M. (2020). Incidência de meningite entre os anos de 2014 a 2019 no estado do Pará. Brazilian Journal of Health Review, 3(5) 11398-11397, 10.34119/bjhrv3n5-002

Paim, A. C. B. Gregio, M. M. \& Garcia, S. P. (2019). Perfil epidemiológico da meningite no estado de santa catarina no período de 2008 a 2018. ACM Arquivo Catarinenses de Medicina 2019 out-dez; 48(4): 111-125, out. -set. 2019. http://www.acm.org.br/acm/seer/index.php/arquivos/article/view/577

Pobb, K. Leite, M. L. Filho, J. S. V. Stocco, C. R. \& Gobbo, B. L. D. (2013). Aspectos epidemiológicos e influência de variáveis climáticas nos casos notificados de meningite em crianças no municipio de ponta grossa - pr, 2002-2011. Revista brasileira de climatologia 9(13). http://dx.doi.org/10.5380/abclima.v13i0.34754

Silva, A. F. T. Da, Valente, F. De S. Sousa, L. D. De Cardoso, P. N. M. Silva, M. A. Da, \& Santos, D. R. Dos. (2021). Estudo epidemiológico sobre meningite bacteriana no Brasil no período entre 2009 a 2018. Revista De Medicina, 100(3), 220-228. https://doi.org/10.11606/issn.1679-9836.v100i3p220-228

Silva, H. C. G. \& Mezarobba, N. (2018). Meningite No Brasil Em 2015: O Panorama Da Atualidade. Arquivos Catarinenses de Medicina. 47(1):34-46. http://www.acm.org.br/acm/seer/index.php/arquivos/article/view/227\#: :text=Ao\%20todo\%2C\%209.282\%20casos\%20de,\%2C2\%20casos\%2F100.000\%20ha bitantes.

Souza, E. F. M. Poça, J. J. G. Ferreira, T. C. R. \& Pinheiro, M. C. (2020). Análise do perfil epidemiológico de meningite na região metropolitana de belém-pa em um período de 10 anos (2010 A 2019). Revista de Patologia do Tocantins, 7(3) 10.20873/uft.2446-6492.2020v7n3p11 